\title{
Laboratory-Scale Evaluation of Single Analyte Bacterial Monitoring Strategies in Water Injection Systems
}

\author{
Mohammed A. Al-Moniee1 ${ }^{*}$, Susanne Juhler², Ketil Sørensen², Xiangyang Zhu1, \\ Thomas Lundgaard ${ }^{2}$, Fahad N. Al-Abeedi ${ }^{1}$, Peter F. Sanders ${ }^{1}$ \\ ${ }^{1}$ Saudi Arabian Oil Company (Saudi Aramco), Dhahran, Saudi Arabia \\ ${ }^{2}$ Danish Technological Institute (DTI), Aarhus, Denmark \\ Email: *mohammed.moniee@aramco.com
}

Received 27 March 2016; accepted 13 June 2016; published 16 June 2016

Copyright @ 2016 by authors and Scientific Research Publishing Inc.

This work is licensed under the Creative Commons Attribution International License (CC BY).

http://creativecommons.org/licenses/by/4.0/

c) (i) Open Access

\section{Abstract}

Microbial activity is the cause of a variety of problems in water injection systems, e.g., microbial corrosion, plugging, and biofouling. Efficient monitoring of Saudi Aramco's vast water injection system requires the development of online and automated technologies for monitoring microbial activities in the system. A previous system review and technology screening has identified five single-analyte strategies [1], which were evaluated in this study with a laboratory-scale setup to determine their applicability for automated determination of microbial activity in the injection water system. Four of the five single-analyte measuring principles tested in the laboratory setup were deemed less suitable for automation and/or reliable for use in the detection of microbial activity in the company injection water system. These four principles were: luminescence assay for adenosine-5'-triphosphate (ATP), detection and electrochemical measurements of $\mathrm{H}_{2} \mathrm{~S}$, determination of $\mathrm{pH}$ by electrochemical sensor, and measurement of oxidation-reduction potential (ORP). The strategy of staining cells with fluorescent DNA dyes, followed by quantification of fluorescence signals, was identified to hold, with proper optimization of DNA staining and fluorescence detection, a very promising potential for integration in automated, online sensors for microbial activity in the injection water system.

\section{Keywords}

Microbial Sensors, DNA Staining, Fluorescent Detection, Automated Monitoring, Injection Water

\footnotetext{
"Corresponding author.
}

How to cite this paper: Al-Moniee, M.A., Juhler, S., Sørensen, K., Zhu, X.Y., Lundgaard, T., Al-Abeedi, F.N. and Sanders, P.F. (2016) Laboratory-Scale Evaluation of Single Analyte Bacterial Monitoring Strategies in Water Injection Systems. Journal of Sensor Technology, 6, 11-26. http://dx.doi.org/10.4236/jst.2016.62002 


\section{Introduction}

Biofilm formation is one of the main causes of water quality deterioration, biofouling, and plugging in water injection systems [1] [2]. In the oil industry, the microbial number and activity are traditionally monitored with conventional growth methods that require manual sampling and handling [3]-[7].

Saudi Arabian Oil Company (Saudi Aramco) has the largest water injection system in the world. To guarantee the continued high quality of the water in the company's seawater injection pipelines, it is necessary to develop and implement a surveillance program that determines the microbiological load and activity at the injection wells. With an online and real-time monitor or biosensor suitable for the harsh environmental conditions at the injection sites, the operators will be able to apply and adjust microbiological control measures promptly in the company vast water injection system.

The research team reviewed the company injection water system, as well as the potential analytical methods that may be applicable for online and automated monitoring of microbial activity. The findings [1] are summarized below as the basis for the current proof of concept study.

\subsection{System Review}

1) The review of the company water injection system indicated the presence of microbial activity in the system with $10^{3}-10^{4}$ cells $\cdot \mathrm{ml}^{-1}$ at the injection sites.

2) The active growth of microbes in the system requires continuous monitoring and control by proper biocide treatment and scraping.

\subsection{Analytical Method Review}

1) A range of technologies were screened for their suitability for automated surveillance of microbial abundance and activity in the water injection system.

2) A challenge in monitoring the microbial activity in the water injection system is the low number of bacterial cells; therefore, a low detection limit is required for chosen analytical strategies.

3) The method review identified five single-analyte strategies for further evaluation in a laboratory-scale setup to ascertain their applicability for monitoring microbial activity. Each of these strategies fulfilled two criteria: a) they were indicators of the microbial activity in the system, and b) they had the potential for automation and application in the injection water system.

4) In prioritized order, the five single-analyte strategies are: microbial DNA staining with nucleic acid stain PicoGreen and/or SYBR Green, adenosine-5'-triphosphate (ATP) detection by a luminometer, measurement of dissolved $\mathrm{H}_{2} \mathrm{~S}$, oxidation-reduction potential (ORP), and $\mathrm{pH}$ by electrochemical sensors.

The overall objective of the study was to develop and implement a technology capable of operating independent of frequent service to enable real-time surveillance of water quality in injection system and at remote injection wells. This paper focuses on developing and proving a single-analyte based monitoring concept for online automated determination of microbial activity in the company's injection water systems.

\section{Materials and Methods}

\subsection{Laboratory-Scale Reactor Setup}

A laboratory-scale reactor was set up to test and evaluate the applicability of the selected single-analyte strategies for monitoring microbial activity and growth. The evaluation was designed to answer the following questions:

1) Does the single-analyte measuring principle provide a stable and reliable signal over an extended monitoring period ( $>2$ months)?

2) Dochanges in analyte concentration correlate with the changes in the levels of microbial growth and activity over time?

3) Are the detection limit and detection range precise enough to detect the changes in the microbial growth and activity within the injection water system?

A photograph and a schematic drawing of the laboratory-scale bacterial detection system are shown in Figure 1. 


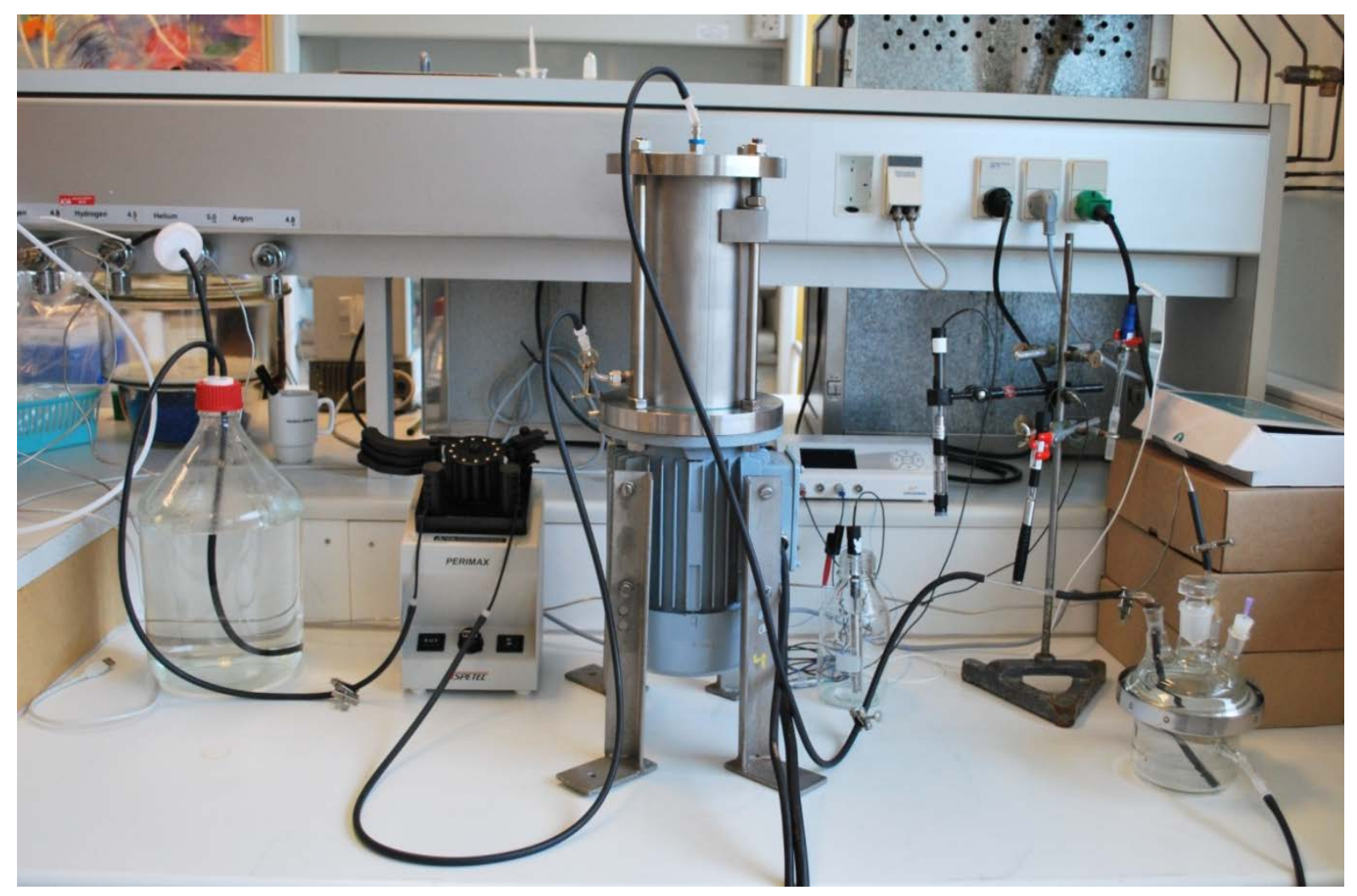

(A)

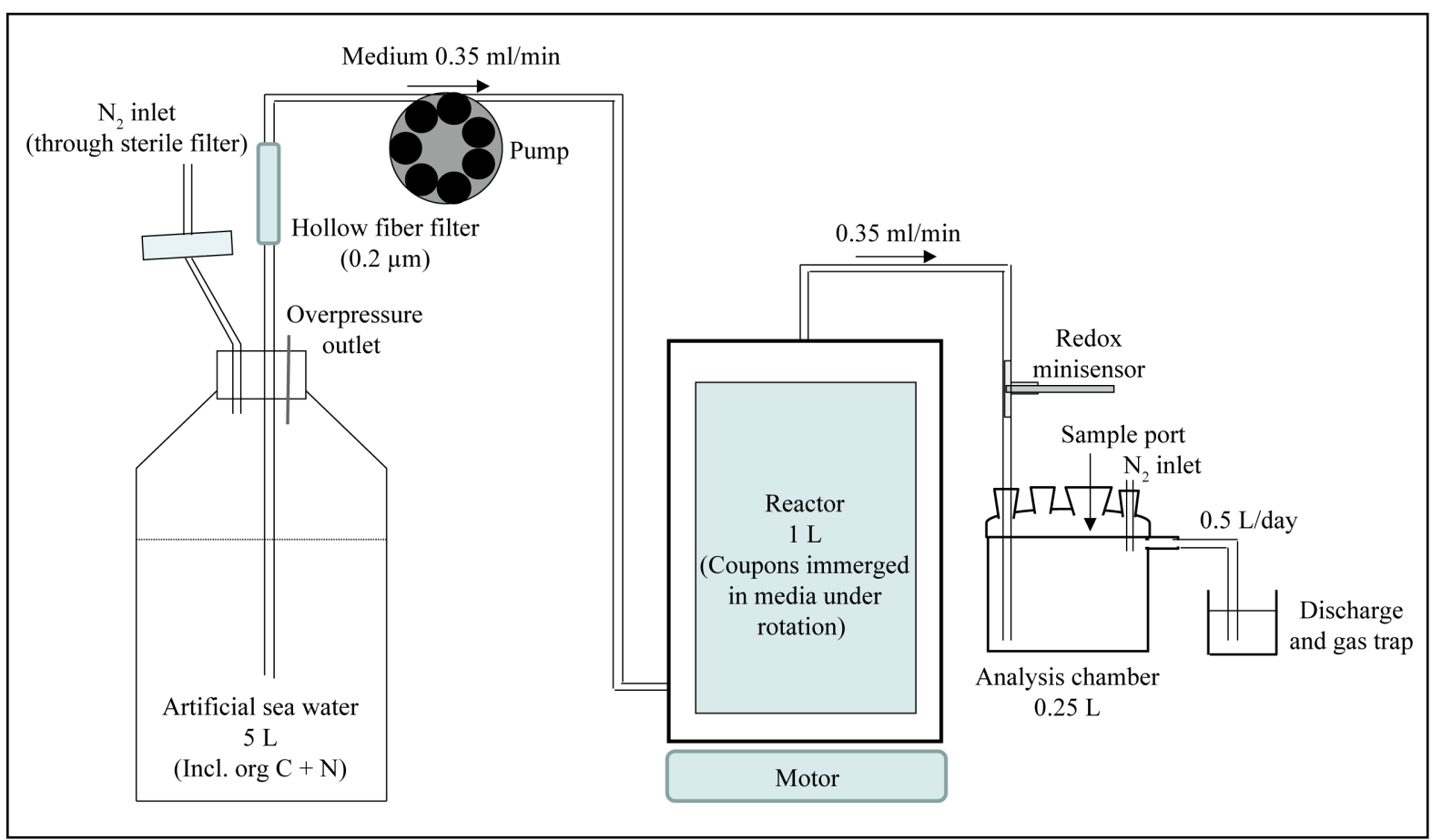

(B)

Figure 1. Photograph (A) and schematic diagram (B) of the laboratory bacterial detection system setup for evaluation of single-analyte monitoring strategies. The system consists of three main parts - a medium bottle to adjust nutrient supply, a rotating reactor for biofilm growth on metal coupon, and an analysis chamber for sampling and testing. 
The reactor setup was designed to simulate the microbiological conditions in an injection water system. A one $\mathrm{L}$ rotating reactor was inoculated with an enrichment culture of scraping solids collected from the Saudi Aramco's injection water pipeline (Figure 2(A)). Carbon steel coupons attached to the inner reactor wall supported biofilm growth and allowed regular biofilm sampling and analysis (Figure 2(B) and Figure 2(C)). Sterile artificial seawater was pumped through the reactor with a flow rate of $0.35 \mathrm{ml} \cdot \mathrm{min}^{-1}$, leading to a residence time of two days, similar to the residence time in the injection water pipeline. Within the reactor, a motor-driven rotator ensured a continuous high-speed current. The heat from the motor resulted in an internal reactor temperature of $45^{\circ} \mathrm{C}-50^{\circ} \mathrm{C}$, close to Saudi Arabian field temperatures. Anoxic conditions were ensured by adding a chemical oxygen scavenger (sodium dithionite) to the seawater medium, and by continuous aeration of the reactor system with nitrogen gas (Figure 1). A chemical oxygen indicator (resazurin) was added to the seawater. All parts of the system were connected through gas-impermeable fluorocarbon rubber tubing (Viton ${ }^{\circledR}$ DuPont Performance Elastomers).

Biofilm growth on the coupons was promoted and controlled through the addition of nutrients (organic carbon, nitrogen, and phosphorus) to the system. Since sulfate-reducing bacteria (SRB) are expected to be among the dominant groups of microorganisms in the company's injection water system [1], Modified Postgate B medium was applied for the growth of SRB [8].

Downstream of the reactor, the outlet passed through a $250 \mathrm{ml}$ glass chamber with gas-tight ports (Figure 1). The chamber allowed for regular inspection of color and odor, and control of outlet flow, as well as sampling of large volumes (necessary for nutrient analysis). From the sampling chamber, an overflow led excess water through a tubing submerged in a discharge tank, which also served to prevent the introduction of oxygen into the reactor system.
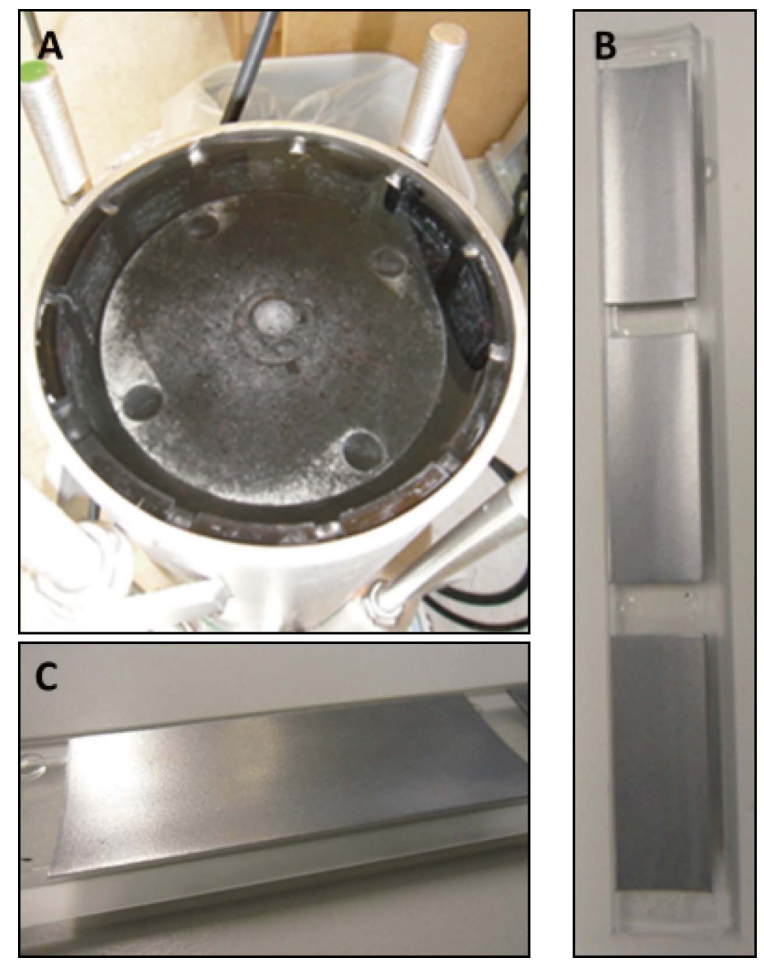

Figure 2. Carbon steel coupons attached to the inside of the rotating reactor. (A) Inside of the inoculated reactor with slides of coupons attached to the inner wall; (B) slide with three coupons attached; and (C) close-up of the clean carbon steel coupon. The rotating reactor is designed to test biofilm growth under the simulated field conditions (2 days of residence time of seawater in the injection pipeline, flow velocity in the injection pipeline, and $45^{\circ} \mathrm{C}-50^{\circ} \mathrm{C}$ Saudi Arabian field temperatures). 


\subsection{Experimental Program}

An overview of the experimental program and analyses conducted in the reactor is provided in Table 1.

Prior to the long-term experimental tests, a pre-test of the reactor setup as well as the single-analyte tests was performed. The reactor system was filled with anoxic artificial seawater to test for stable flow, gas impermeability, and general long-term setup stability. The PicoGreen DNA staining assay was applied on cell cultures to test cell wall penetration and detection limits [9]. The electrochemical $\mathrm{H}_{2} \mathrm{~S}, \mathrm{pH}$, and ORP minisensors were tested on standard solutions with known analyte concentrations to ensure a linear and reliable signal and determine analyte detection limits.

The correlation between measured single-analyte signals and levels of microbial growth and activity was tested during a 65-day reactor experiment. In the first six days of the test period, the reactor was fed with artificial seawater containing a high organic substrate concentration $\left(13 \mathrm{~g} \cdot \mathrm{L}^{-1}\right)$ (Table 2). This ensured a high growth potential and good biofilm establishment at inoculation with enrichment culture prepared from the company pipeline scraping solids at Day 7. Following inoculation, controlled changes in the microbial growth and activity were introduced through the regulation of nutrient levels fed to the reactor. During 49 days, the concentration of organic substrates was gradually decreased from very high $\left(13 \mathrm{~g} \cdot \mathrm{L}^{-1}\right)$ to the levels naturally found in the injection

Table 1. Experimental program and analyses for evaluation of single-analyte monitoring strategies.

\section{Experimental Program}

\section{1) Initial system and method tests}

- Test of reactor system: flow, gas permeability.

- Test of detection limits and procedure for DNA staining: PicoGreen and SYBR Green.

- Test of electrochemical sensor detection limits.

\section{2) Reactor inoculation}

- Preparation of an enrichment culture from artificial seawater media inoculated with pipeline scraping solids.

- Inoculation of reactor system for one day to promote biofilm establishment.

\section{3) Experimental evaluation of single-analyte strategies}

- Regulation of biofilm growth through changes in nutrient load as well as biocide treatment, while determining analyte concentrations in the water phase.

- Control analyses of planktonic cell growth and microbial biofilm by quantitative polymerase chain reaction (qPCR) technique.

- Test of correlation between microbial growth and analyte concentrations.

- Test of detection limits of single-analyte strategies.

- Selection of 1 or 2 single-analyte strategies suitable for monitoring microbial activity in the system.

\begin{tabular}{|c|c|c|}
\hline \multicolumn{3}{|c|}{ Analytes monitored } \\
\hline & Analyte & Method \\
\hline \multirow[t]{5}{*}{ Water } & DNA & PicoGreen and SYBR Green assay \\
\hline & ATP & ATP luminometer \\
\hline & $\mathrm{H}_{2} \mathrm{~S}$ & Electrochemical minisensor \\
\hline & ORP & Electrochemical minisensor \\
\hline & $\mathrm{pH}$ & Electrochemical minisensor \\
\hline \multicolumn{3}{|c|}{ Control measures for microbial growth and activity } \\
\hline & Analyte & Method \\
\hline \multirow[t]{2}{*}{ Water } & Planktonic population & qPCR and 4,6-diamindino-2-phenylindole (DAPI) staining method \\
\hline & Nutrient consumption & Total Organic Carbon (TOC) and Total Nitrogen (TN) analyses \\
\hline \multirow[t]{2}{*}{ Coupons } & Sessile population & DAPI staining method \\
\hline & Biofilm growth & Wet weight, dry weight, and organic content analyses \\
\hline
\end{tabular}


Table 2. Organic substrate supply and biocide treatment during the experimental period.

\begin{tabular}{ccc}
\hline $\begin{array}{c}\text { Time from experiment } \\
\text { start (days) }\end{array}$ & $\begin{array}{c}\text { Organic substrates } \\
\left(\mathrm{g} \cdot \mathrm{L}^{-1}\right)\end{array}$ & $\begin{array}{c}\text { Biocide addition } \\
(\mathrm{ppm})\end{array}$ \\
\hline 1 & 13.0 & - \\
7 & 1.12 & - \\
15 & 0.14 & - \\
28 & 0.03 & - \\
42 & 0.003 & - \\
49 & 1.12 & - \\
61 & 1.12 & 2000 \\
64 & 1.12 & 4000 \\
\hline
\end{tabular}

water system $\left(0.003 \mathrm{~g} \cdot \mathrm{L}^{-1}\right)$. Throughout this period the outlet water from the reactor system was analyzed by use of the selected single-analyte strategies, and the signals were compared to control analyses of the microbial biofilm and planktonic growth and activity in the system (Table 1). Besides testing the correlation between singleanalyte measures and microbial growth and activity, the test served to determine the detection limits of the single-analyte strategies applied.

During the final five days of the experimental period, the system was treated with biocide \#1415 (Table 2). Prior to the biocide treatment, the reactor had been supplied with a high substrate concentration for 12 days, to attain high microbial growth and activity. The biocide treatment was given in two separate doses, first in a 2000 ppm dosage, after which the single-analyte signals as well as response in microbial growth was followed for three days, and then in a $4000 \mathrm{ppm}$ dosage, to ensure a complete stop of microbial activity. This test served to evaluate the signal response time of the single-analyte strategies.

\subsection{Single-Analyte Monitoring}

To ensure the measurement of real-time conditions inside the reactor, single-analyte monitoring was performed directly in the reactor outlet. The end of the reactor outlet tubing was temporarily disconnected from the analysis chamber (Figure 1) and transferred to a sterile $50-\mathrm{ml}$ Falcon tube. Single-analyte analyses were performed in the outlet running into the tube. Samples for DNA staining with PicoGreen and SYBR Green were fixed with formaldehyde and stored in the refrigerator until analysis. The fixated cell samples were treated with a nonionic surfactant Triton X-100 (Sigma-Aldrich) to render cell membranes permeable to the DNA stain [10]. Samples were subsequently stained with PicoGreen or SYBR Green, and the fluorescence signal was measured on a qPCR machine for enumeration of microbial population [9] [11] [12].

Concentrations of ATP were measured by collecting a $100 \mu \mathrm{L}$ sample using an Aquasnap ${ }^{\mathrm{TM}}$ pen (Food Diagnostics), and the bioluminescence signal was measured in a System SURE Plus ${ }^{\mathrm{TM}}$ manometer (Hygiena).

Electrochemical minisensor measurements of $\mathrm{H}_{2} \mathrm{~S}$ and $\mathrm{pH}$ were performed by submerging the sensors in the reactor outlet collected in the sterile Falcon tube. The sensors were left to log the signal during sampling of 50 $\mathrm{ml}$. The signal was automatically logged in a PC using a Unisense Multimeter ${ }^{\mathrm{TM}}$. Before each measurement, the sensors were calibrated in solutions of known analyte concentrations. For ORP measurement a minisensor was incorporated in a glass flow tube, which was connected directly to the reactor outlet tubing for continuous signal logging throughout the experimental period (Figure 1). Once a week, the sensor was disconnected from the setup and calibrated in solutions of known ORP.

\subsection{Reference Measures of Microbial Numbers and Activity}

In parallel with the single-analyte monitoring, samples were collected for control measures of microbial activity and growth. To determine the microbial activity, samples collected from the reactor inlet and outlet were analyzed chemically for concentrations of TOC and TN. The microbiological nutrient consumption was calculated 
as the difference between inlet and outlet TOC and TN concentrations. The planktonic microbial growth was determined through cell enumeration in water samples collected from the reactor output. Part of the sample was filtered and used for cell number quantification by qPCR analysis specific for the Bacteria16S rRNA gene [7]. The rest of the sample was fixed in formaldehyde, filtered, and stained with DAPI [13]-[15], and the cell number was counted by epi-fluorescence microscopy.

For analysis of biofilm growth, three coupons were sampled from the reactor. Biofilm was scraped off of the coupons and weighed on a four-decimal scale. The biofilm from one coupon was used for determining dry weight and organic matter content. The biofilm from the other two coupons was used for cell density analysis by qPCR and DAPI counts, respectively. During each sampling, the coupons were exchanged with new clean coupons, which were collected during the next coupon sampling. In this way, biofilm growth during a known time interval and stable substrate load could be determined. As coupon sampling involved the introduction of oxygen into the reactor system, the sampling frequency was minimized to four times during the experimental period.

\section{Results and Discussion}

In this study, five single-analyte strategies were evaluated experimentally so as to select the best performing candidate for further automation and incorporation into a full-scale microbial monitoring sensor.

\subsection{Reference Measures of Microbial Growth and Activity}

\subsubsection{Planktonic Cell Growth}

The qPCR analysis of reactor outlet samples showed a clear decrease in the number of planktonic cells during the first 49 days of the experimental period, which corresponded well with the gradually reduced organic substrate supply through this period (Figure 3).

Toward the end of the experiment, when the first biocide dosage was added at $2000 \mathrm{ppm}$, the cell numbers increased again. The increase in planktonic cell numbers following biocide addition may appear paradoxical, but there are several possible explanations:

1) The efficient kill effect may cause a release of cells from biofilm on the reactor's inner surfaces.

2) It may have been caused by enhanced microbial growth in response to the nutrients (C, N, and P) present in the biocide mixture.

3) It may have been a delayed effect of the enhanced organic substrate supply at Day 49, since reactor flow problems disturbed the substrate supply between Day 50 and Day 57.

During injection of the first biocide dosage into the reactor, unforeseen problems arose, as the clamp holding back the liquid in the reactor did not suffice, and a minor amount of liquid was escaping the reactor after biocide

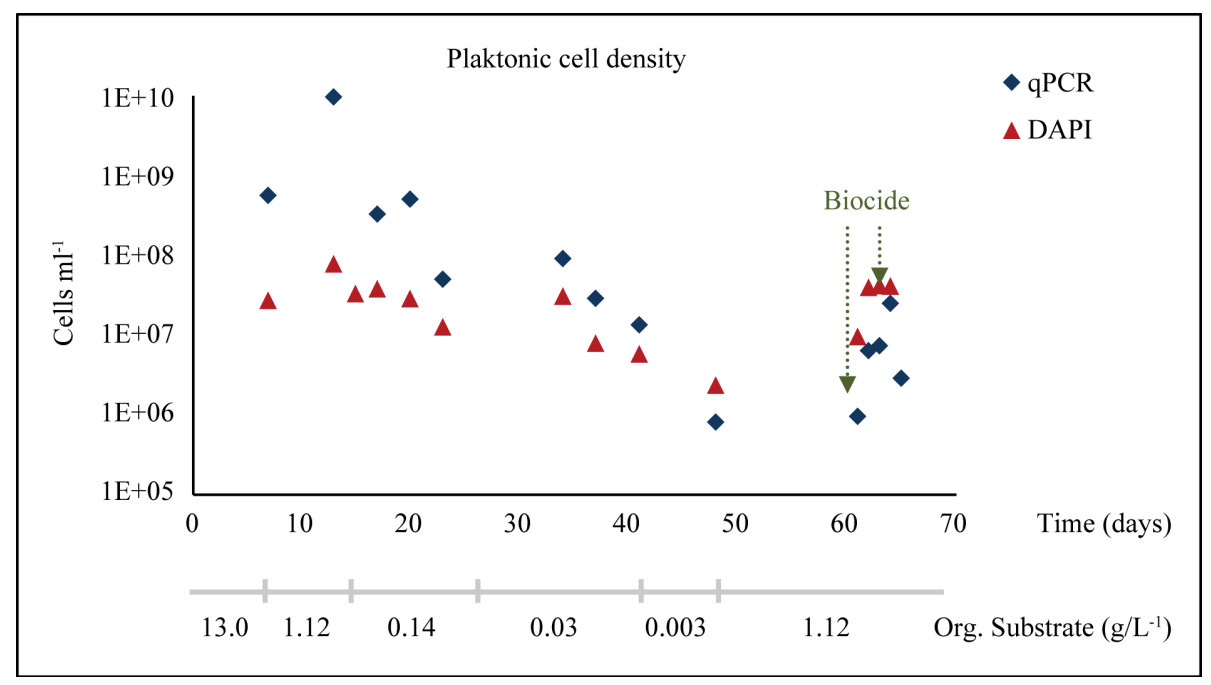

Figure 3. Planktonic cell numbers determined by qPCR analysis and DAPI counts. The lower X-axis shows the organic substrate supply (in $\mathrm{g} \cdot \mathrm{L}^{-1}$ ) to the reactor. The green arrows indicate biocide addition (2000 ppm and 4000 ppm, respectively). 
injection. This liquid may have contained a high fraction of the biocide dosage, and the resulting biocide concentration within the reactor might have been lower than $2000 \mathrm{ppm}$. Therefore, the response in cell numbers and activity following this biocide treatment must not be interpreted as a definitive test of the biocide efficiency at a 2000 ppm concentration.

After addition of the second biocide dosage at $4000 \mathrm{ppm}$, a fast decrease in the cell number was observed (Figure 3). This decrease corresponded to the wash-out rate from the reactor (the half-life rate was 1.09 days at the given volume and flow rate), and indicated a complete stop in cell growth.

Cell numbers obtained by DAPI counts generally showed very good correlation with the qPCR results (Figure 3). In the beginning of the experimental period, the DAPI numbers were somewhat lower than the qPCR numbers. This difference is most possibly caused by insufficient dilution of the first samples stored for DAPI analysis, as cell numbers showed to be much higher than initially anticipated.

\subsubsection{Biofilm Growth}

Biofilm coupons were sampled at Day 24, 41, 48, and 56. On all coupon samples, biofilm formation was clearly visible (Figure 4). Biofilm analyses showed a dry matter content of $\sim 60 \%$, and an organic matter content of $20 \%$ - 30\% of the dry weight (Table 3). The residual $70 \%-80 \%$ of the dry weight may primarily have comprised corrosion products from the carbon steel coupon.

No clear-cut increase or decrease was observed in the biofilm cell density during the experimental period, and at all sampling times; the cell density was roughly $3.5 \times 10^{6} \mathrm{cells} \cdot \mathrm{cm}^{-2}$ (Table 3). This indicated that the biofilm cell density was kept in a steady state through the slough of biomass during biofilm growth.

Roughly estimated, the number of cells growing in biofilm within the reactor was $\sim 10^{9}$ cells. During the high organic substrate supply in the beginning of the experimental period, only a minor fraction of the microbiological biomass was therefore located in the biofilm. During the period of low substrate supply, which was more similar to the in-field situation, approximately $50 \%$ of the reactor biomass was comprised by biofilm (Figure 3 compared to Table 3).

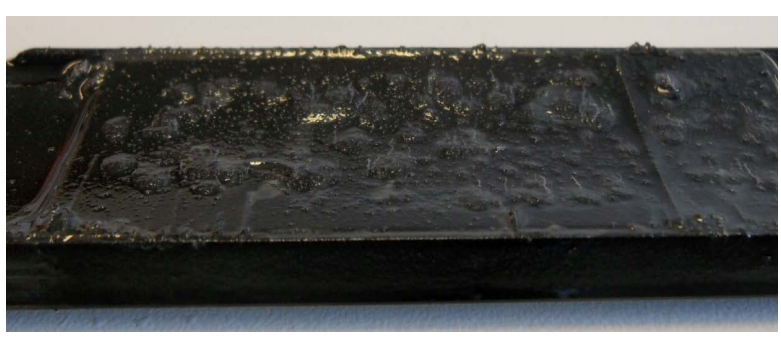

(A)

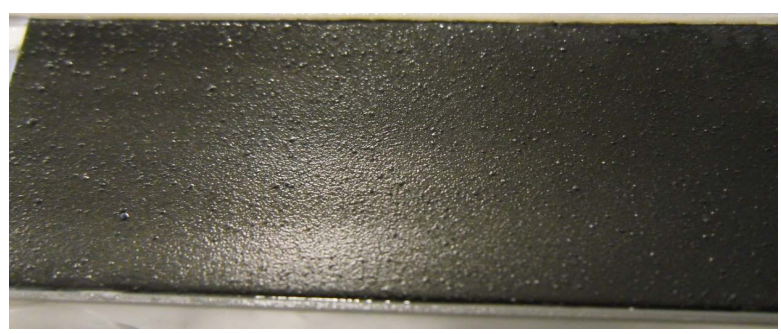

(C)

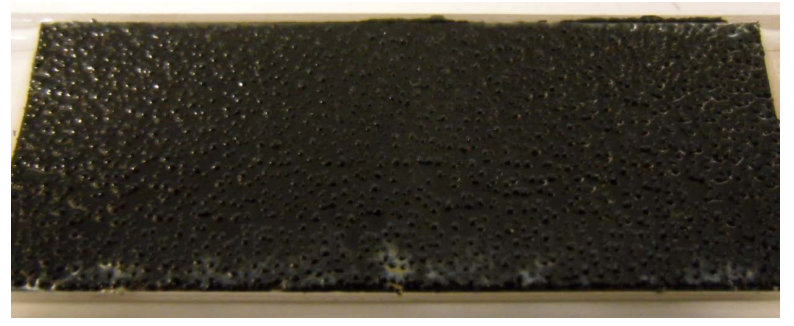

(B)

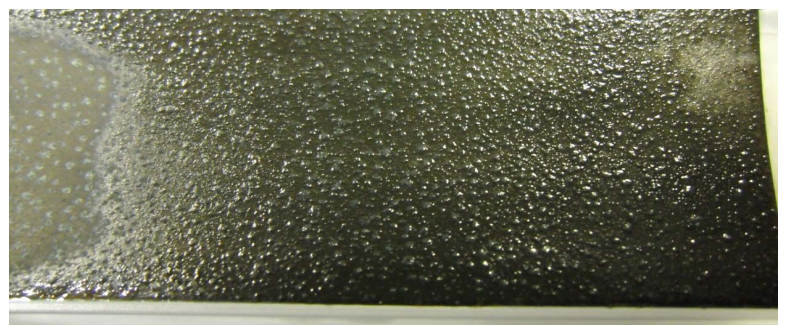

(D)

Figure 4. Coupons sampled from the reactor. The coupons were sampled on Day 24 (A), Day 41 (B), Day 48 (C), and Day 56 (D).

Table 3. Biofilm dry weight, organic matter content, and cell density from coupon samples.

\begin{tabular}{ccc}
\hline $\begin{array}{c}\text { Dry weight content } \\
\text { (\% of wet weight) }\end{array}$ & $\begin{array}{c}\text { Organic matter content } \\
\text { (\% of dry weight) }\end{array}$ & $\begin{array}{c}\text { Cell density } \\
\text { (cells cm }{ }^{-2} \text { ) }\end{array}$ \\
\hline$\sim 60$ & $20-30$ & $\sim 3.5 \times 10^{6}$ \\
\hline
\end{tabular}




\subsubsection{Microbial Activity}

The inlet and outlet concentrations of TOC and TN were determined by chemical analyses with a precision of $1-3 \mathrm{mg} \cdot \mathrm{L}^{-1}$. During the experimental period, no significant differences were detected between the inlet and outlet TOC and TN concentration, suggesting that the microbial activity within the reactor corresponded to a TOC and TN consumption of $<1-3 \mathrm{mg} \cdot \mathrm{L}^{-1}$.

\subsection{Monitoring Single-Analyte Signals}

\subsubsection{Fluorescent DNA Staining}

Initial pre-tests showed that intact E. coli cells treated with Triton X-100 could subsequently be successfully stained with PicoGreen (Figure 5(A)). The same result was obtained for planktonic cells collected from the reactor (Figure 5(B)). A comparison between microscopic cell counts, obtained with a PicoGreen staining after Triton X-100 treatment and a reference DAPI staining of the same E. coli culture, respectively, showed a PicoGreen staining efficiency of $\sim 100 \%$.

Staining of PicoGreen and the SYBR Green was performed on a dilution series of an $E$. coli pure culture, and the fluorescence signal was measured in a qPCR machine. For both DNA stains, the results showed a fine correlation between the cell density and the fluorescence signal (Figure 6). This correlation was sustained down to a lower detection limit of $10^{6}$ and $10^{4}$ cells $\cdot \mathrm{ml}^{-1}$, for the PicoGreen and the SYBR Green analysis, respectively. Below this cell density, the fluorescence signal did not exceed the signal emitted from a blank sample.

PicoGreen and SYBR Green analysis of reactor samples collected throughout the experimental period resulted in a pattern, which correlated well with the density of planktonic cells determined by qPCR analysis (Figure 3 and Figure 7(B)). In agreement with the qPCR cell enumeration, the fluorescence signal obtained by PicoGreen and SYBR Green staining decreased during the period with gradually reduced organic substrate supply to the reactor, and increased again towards the end of the experiment, where substrate supply was enhanced and biocides were added. During the period with low organic substrate supply, the cell density approached the detection limit of the DNA staining methods (i.e., a background signal of 1800 and 2000 for the PicoGreen and the SYBR Green analysis, respectively). The decrease in the planktonic cell number between Day 30 and 50 was therefore not clearly detectable with either the PicoGreen or the SYBR Green staining technique (Figure 7(A)).

When the fluorescence signal obtained by PicoGreen and SYBR Green staining was plotted as a function of planktonic cell numbers obtained by qPCR analysis, a good correlation was observed between the fluorescence signal and the number of cells in the sample (Figure 7(B)). Five sampling points (marked with a grey circle) fell somewhat outside this correlation by showing a higher fluorescence signals per cell. While all other samples had been stored in formaldehyde fixation in the refrigerator for at least 20 days prior to analysis, these five samples were collected at the very end of the experimental period, i.e., only a few days prior to the DNA staining analysis. This observation may indicate that higher signal intensities can be obtained, if long-time storage is avoided, as would be the case for online monitoring in the company pipeline systems.

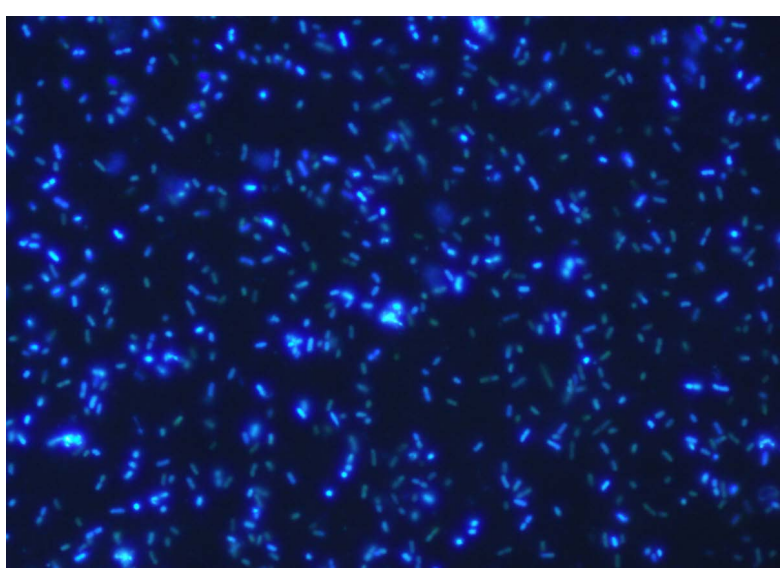

(A)

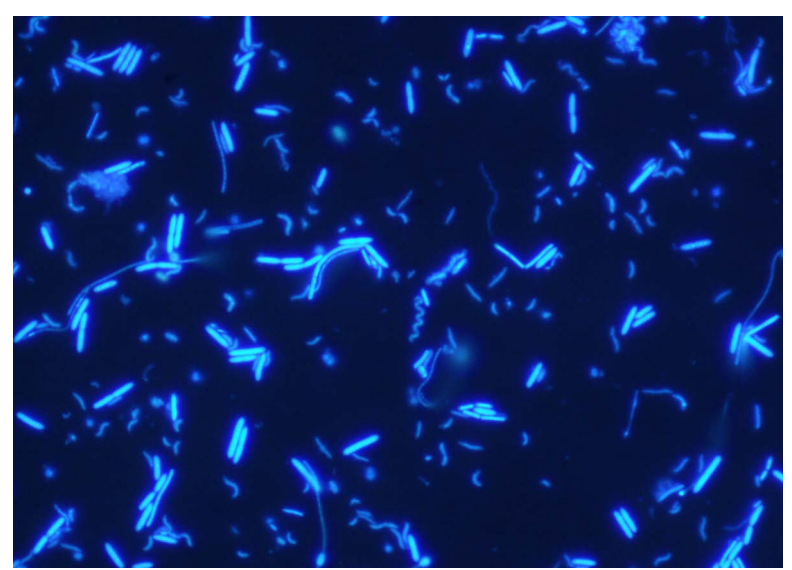

(B)

Figure 5. Microscopic examination of the penetration of PicoGreen into intact cells. (A) PicoGreen staining of cells from an E. coli pure culture; (B) PicoGreen staining of planktonic cells sampled from the reactor. 


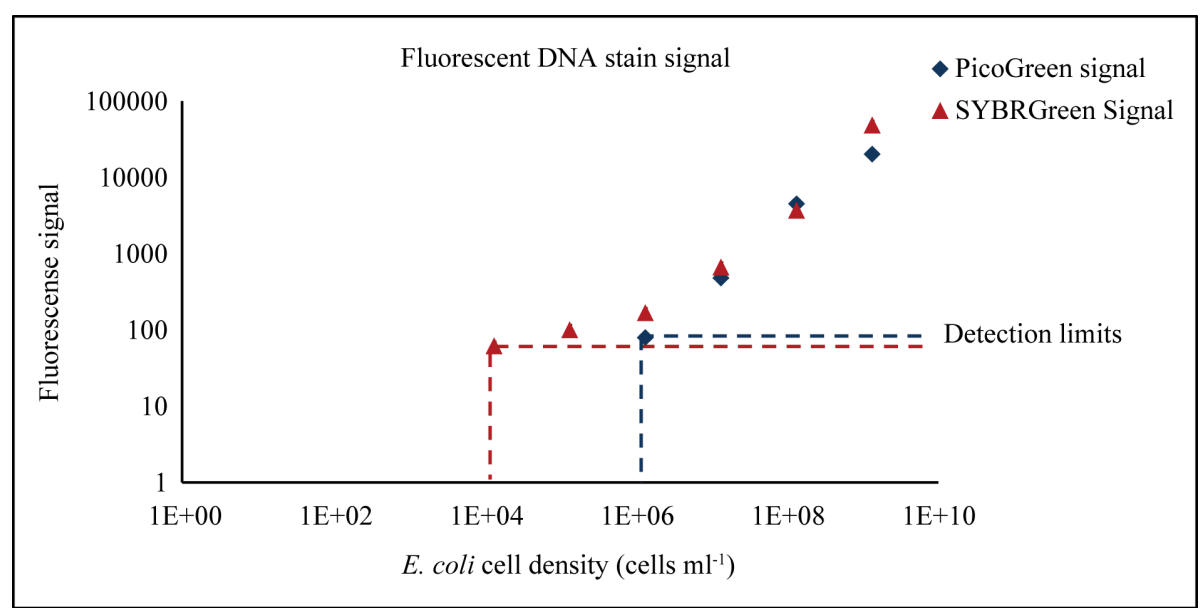

Figure 6. Correlation between fluorescent signal and cell density, when staining a serial dilution of cells from an $E$. coli pure culture with PicoGreen and SYBR Green, respectively. The background signal (from a blank sample) has been subtracted from the fluorescence values.
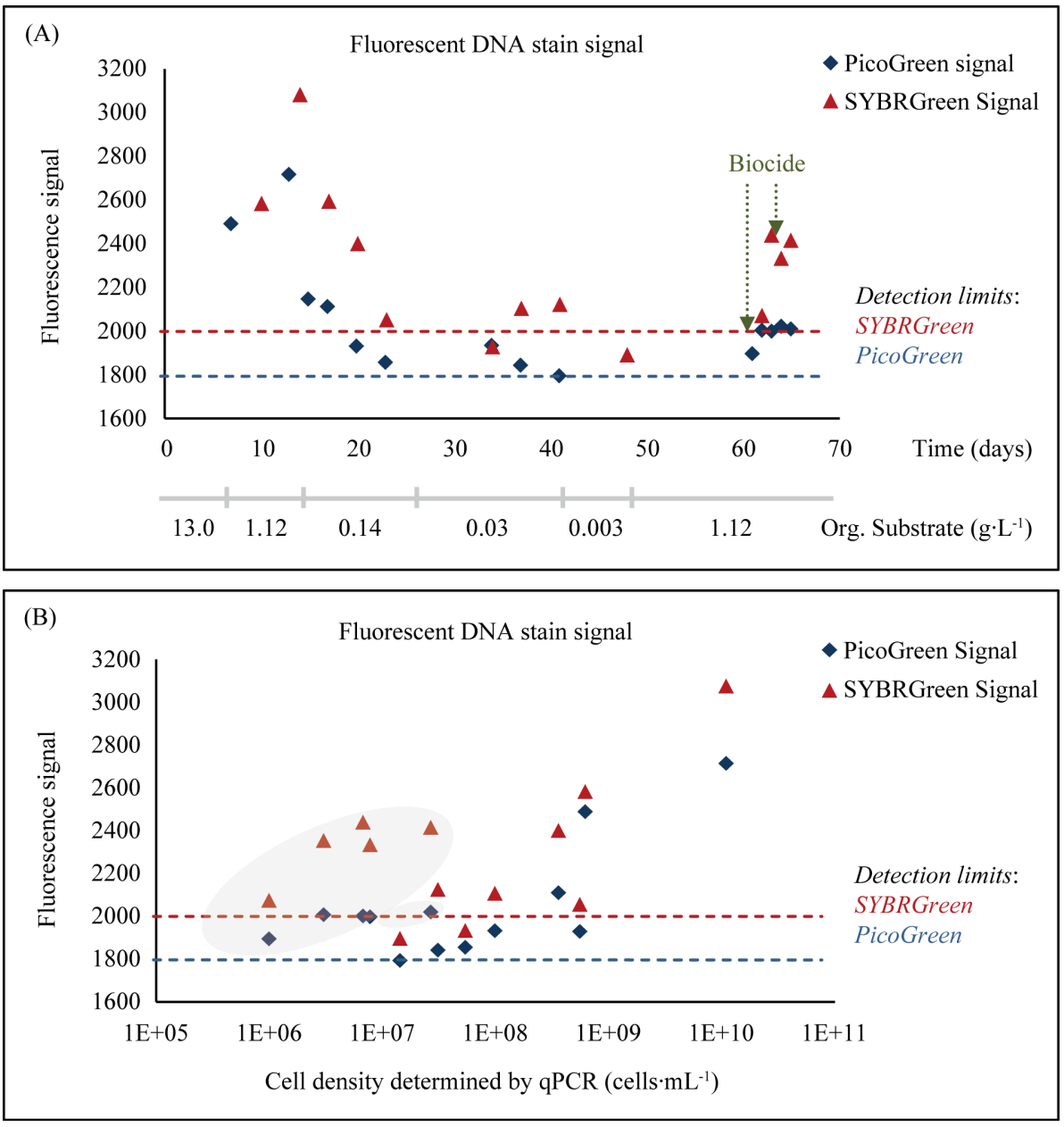

Figure 7. Fluorescence signals obtained by PicoGreen and SYBR Green staining of planktonic cell samples collected from the reactor. (A) Fluorescence signal as a function of time, (B) correlation between fluorescence signals and cell numbers determined by qPCR. In (A), the lower X-axis shows the organic substrate supply (in $\mathrm{g} \cdot \mathrm{L}^{-1}$ ) to the reactor. The green arrows indicate biocide addition (2000 ppm and 4000 ppm, respectively). In (B), the grey circle marks samples that were collected during the last five days of the experiment, immediately prior to the DNA stain analysis. 
As shown in Figure 7(B), the detection limit of the PicoGreen and SYBR Green analysis applied on cells sampled from the reactor was around $10^{7} \mathrm{cell} / \mathrm{ml}$, and so somewhat higher compared to the detection limits determined for the $E$. coli culture (Figure 6). This difference may be caused by the much larger cell size of the $E$. coli cells, but may also be due to the longer storage time for the reactor samples. In any case, avoiding long-time storage of samples combined with instrumentally improved fluorescence detection will be necessary to bring down the detection limit to a range that is relevant for cell detection in Saudi Aramco's injection water pipeline systems, i.e., $10^{3}-10^{4}$ cells $\cdot \mathrm{ml}^{-1}[1]$.

\subsubsection{ATP Bioluminescence Assay}

A general product of the activity in living organisms is energy, which is bound in the form of ATP [16] [17]. Thus, the concentration of ATP can be used as a measure of the overall metabolic activity.

Due to the availability of ATP analysis equipment, measurement of the ATP concentration in the reactor outlet was concentrated to the last 29 days of the experimental period (Day 37 - 65, Figure 8(A)).

The overall pattern of the ATP profile roughly followed the cell densities measured by qPCR analysis (Figure 8(A) compared to Figure 5). Low ATP levels were observed from Day 37 to Day 48, where the organic substrate supply was low and decreasing. A slight increase in the ATP level could be detected towards Day 61, as the substrate supply was again enhanced (Figure 8(A)). At addition of the first biocide dosage, the ATP level rose markedly, after which it decreased steeply during the subsequent two days. After addition of the second
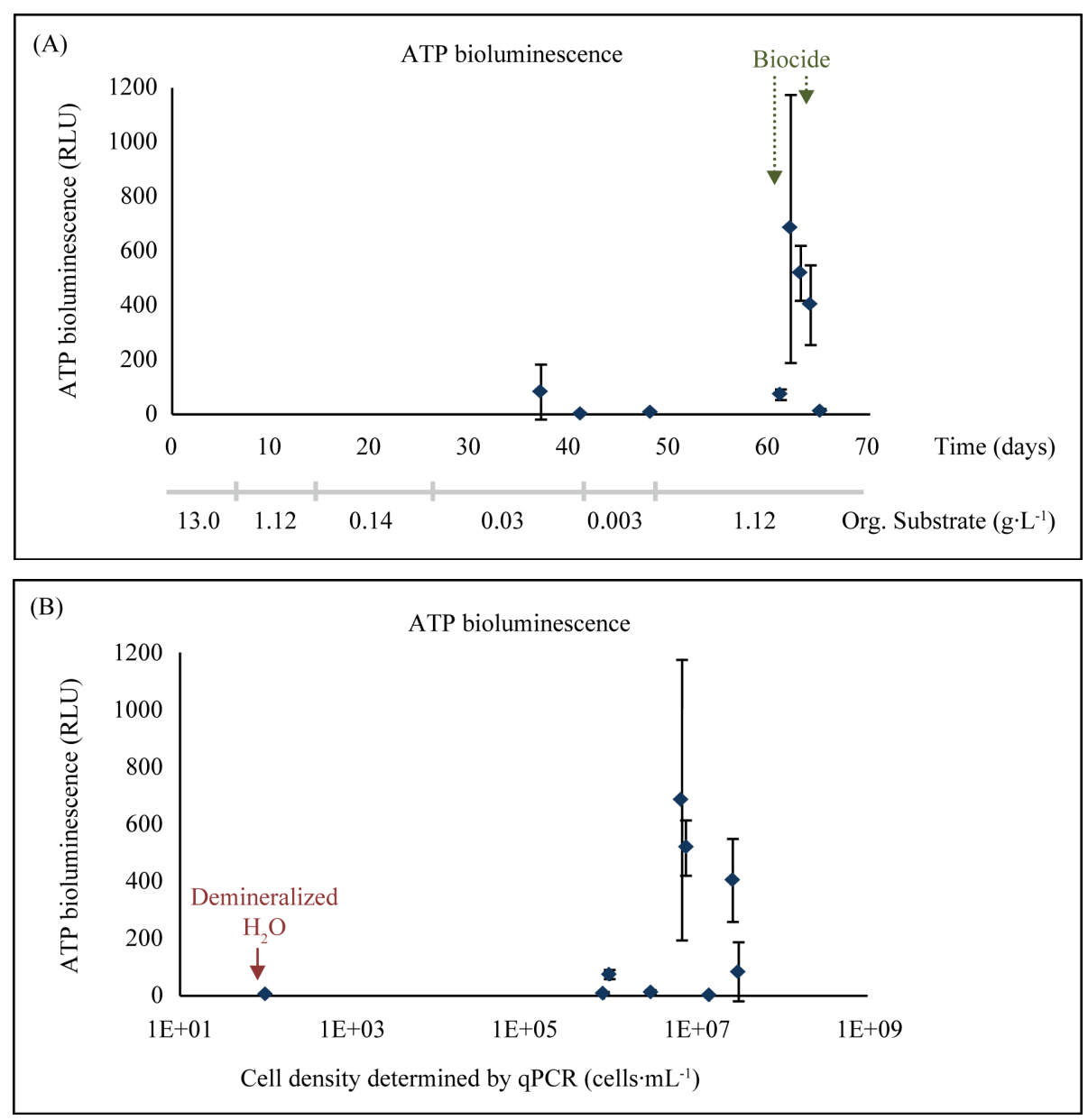

Figure 8. ATP bioluminescence signal measured in relative light units (RLU). (A) The ATP signal as a function of time, (B) correlation between ATP signal and cell numbers determined by qPCR. In (A), the lower X-axis shows the organic substrate supply (in $\mathrm{g} \cdot \mathrm{L}^{-1}$ ) to the reactor. The green arrows indicate biocide addition (2000 ppm and 4000 ppm, respectively). Error bars represent standard deviations from 3-7 repetitive measurements on the same sample. 
biocide dosage, the ATP level had dropped to the same levels as observed during very low substrate supply.

This pattern indicates that the ATP level is a good indicator of overall microbial activity in the system. The individual measurements were associated with very high variations in the ATP signal (c.f. error bars shown in Figure 8), and often each sample had to be analyzed 3 - 7 times before a reliable mean value was attained. The low ATP levels measured in the reactor outlet (corresponding to $10^{6}-10^{7}$ cells $\mathrm{ml}^{-1}$ ) resulted in the same ATP values as when analyzing a sample of demineralized water (Figure $8(B)$ ). The ATP bioluminescence technology does not appear sensitive or reliable enough for meaningful application in the injection water system.

\subsubsection{Electrochemical Sensor Measurements of $\mathrm{H}_{2} \mathrm{~S}$}

Under the anoxic and sulfate-rich conditions prevailing in the company injection water pipeline system, the microbiological activity is expected to be dominated by SRB. The SRB gains energy from the oxidation of organic carbon with $\mathrm{SO}_{4}^{2-}$ present in the seawater, a process which produces $\mathrm{CO}_{2}$ and $\mathrm{H}_{2} \mathrm{~S}$ [18]. As an indicator of SRB activity, the concentration of $\mathrm{H}_{2} \mathrm{~S}$ was therefore analyzed.

Initial pre-tests of the electrochemical $\mathrm{H}_{2} \mathrm{~S}$ sensor showed a precise and fine-scale resolution of the sensor signal, which responded linearly down to an $\mathrm{H}_{2} \mathrm{~S}$ concentrations of $<1 \mu \mathrm{M}$ (Figure 9). Though the sensor applied for this laboratory-scale reactor experiment is not robust enough for in-field application, the results demonstrated that $\mathrm{H}_{2} \mathrm{~S}$ could be electrochemically monitored down to concentrations well below the $\mathrm{H}_{2} \mathrm{~S}$ level of 32 $\mu \mathrm{M}$ detected in the injection water system [1].

The development in the $\mathrm{H}_{2} \mathrm{~S}$ signal during the reactor experiment (Figure 10(A)) correlated to a large degree with the cell abundance measured by qPCR (Figure 5), showing a decrease in the $\mathrm{H}_{2} \mathrm{~S}$ signal from Day 1 to Day 50 as the organic substrate supply was gradually reduced, an increased signal around Day 61 where the substrate concentration was again enhanced, and a marked signal increase followed by a steep signal decrease during the biocide treatment (Figure 10(A)). During the period with very low organic substrate supply, similar to the TOC concentration detected in the injection water system $\left(0.003 \mathrm{~g} \cdot \mathrm{L}^{-1}\right)$, a $\mathrm{H}_{2} \mathrm{~S}$ concentration of $27 \mu \mathrm{M}$ was measured (Figure 10(A)). This concentration corresponded very well with the concentration of $32 \mu \mathrm{M} \mathrm{H}_{2} \mathrm{~S}$ detected at the injection well [1].

Compared to the cell abundance measured by qPCR, the $\mathrm{H}_{2} \mathrm{~S}$ signal appeared to respond faster. During the initial decrease in organic substrate supply from $13.0 \mathrm{~g} \cdot \mathrm{L}^{-1}$ to $1.12 \mathrm{~g} \cdot \mathrm{L}^{-1}$, the $\mathrm{H}_{2} \mathrm{~S}$ signal showed a fast and steep drop around Day 10 (Figure 10(A)), while the cell density only decreased slowly (Figure 5). Likewise, after the first biocide dosage, the cell density was still increasing for a few days, while the $\mathrm{H}_{2} \mathrm{~S}$ signal increased for only one day, after which it showed a steep drop. The rate of this signal decrease corresponded to the wash-out rate from the reactor (calculated from the reactor volume and flow rate), indicating a completely inhibited $\mathrm{H}_{2} \mathrm{~S}$ production.

While a very fine correlation was observed between the $\mathrm{H}_{2} \mathrm{~S}$ signal and the cell density during slow changes in the system (i.e., gradually changed nutrient supply) (Figure 10(A)), only very little overall correlation between the $\mathrm{H}_{2} \mathrm{~S}$ signal and the cell density was observed (Figure 10(B)). Samples of same cell density could

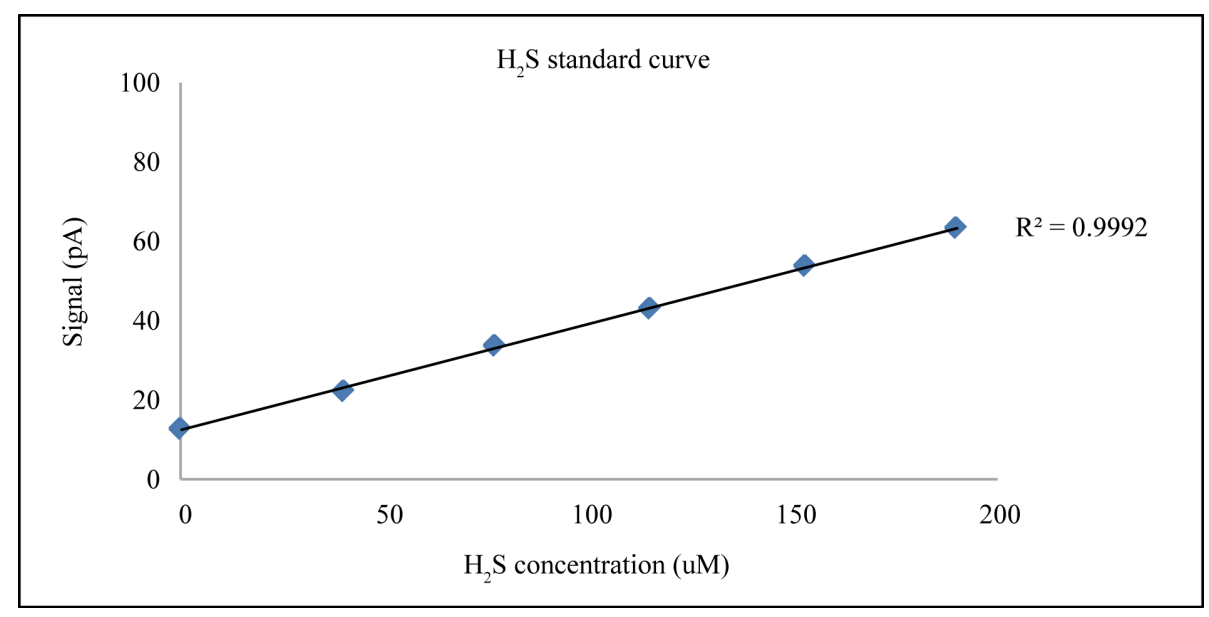

Figure 9. Signal response of the sensor to low $\mathrm{H}_{2} \mathrm{~S}$ concentrations. 

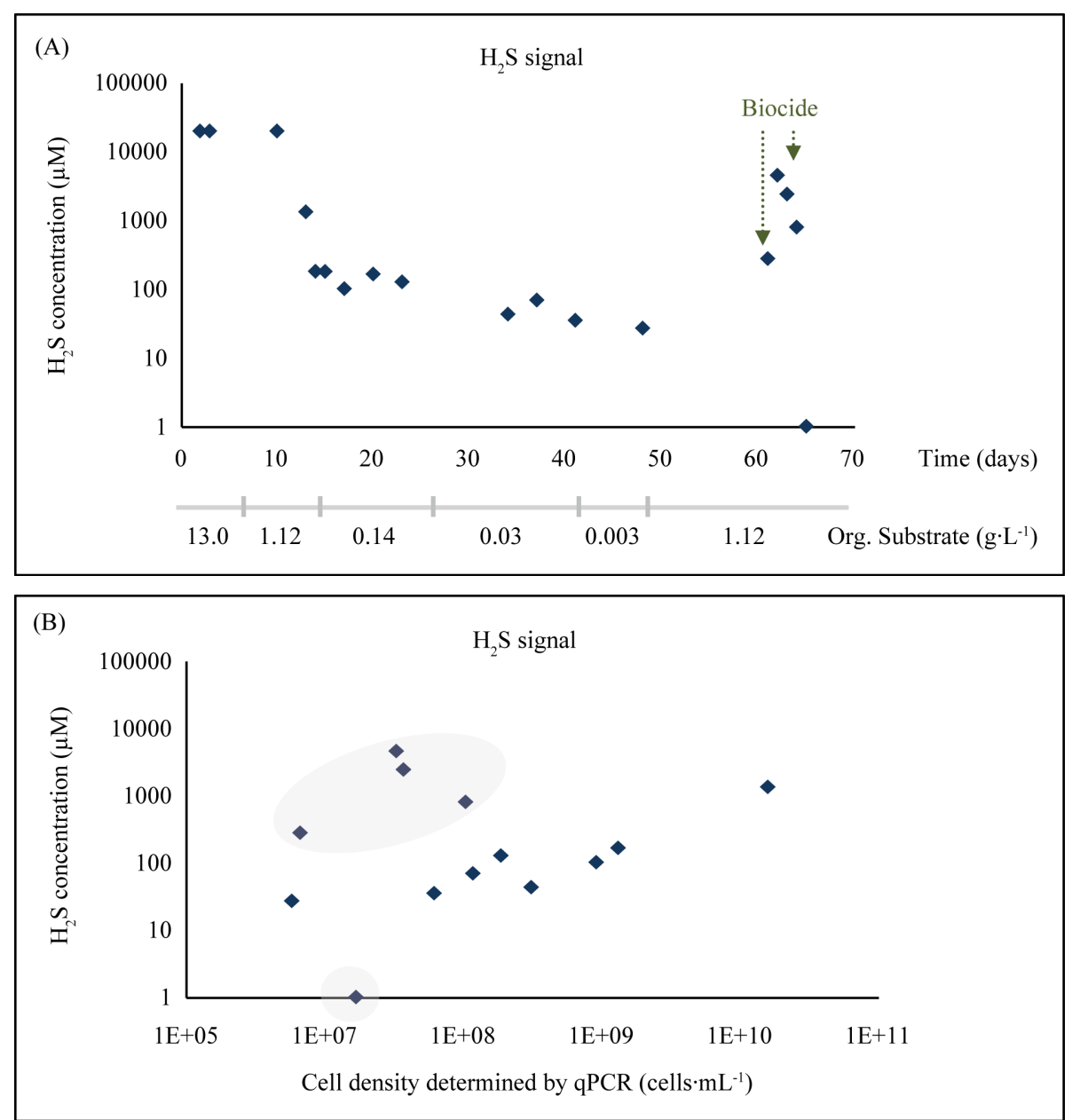

Figure 10. Concentration of $\mathrm{H}_{2} \mathrm{~S}$ measured by electrochemical sensor. (A) The $\mathrm{H}_{2} \mathrm{~S}$ signal as a function of time, (B) correlation between $\mathrm{H}_{2} \mathrm{~S}$ signal and cell numbers determined by qPCR. In (A), the lower $\mathrm{X}$-axis shows the organic substrate supply (in $\mathrm{g} \cdot \mathrm{L}^{-1}$ ) to the reactor. The green arrows indicate biocide addition (2000 ppm and 4000 ppm, respectively). In (B), grey areas mark the analyses performed during biocide treatment.

obviously express very different activity rates, as indicated by sample points marked with the grey circles in the graph (Figure 10(B)). The miscorrelation was most pronounced during sudden changes in the system (i.e., biocide treatment). Therefore, electrochemical sensor measurement of $\mathrm{H}_{2} \mathrm{~S}$ was not considered as a suitable singleanalyte strategy for monitoring the microbial activity in the injection water system.

\subsubsection{Electrochemical Sensor Measurements of $\mathrm{pH}$}

In general, microbial activities are based on processes that either consume or produce $\mathrm{H}^{+}$[19] [20]. A simple measure of microbial activity in the system would therefore be to monitor the $\mathrm{pH}$ of the injection water and compare it to that of the water entering the system at the treatment plant. $\mathrm{pH}$ was therefore monitored during the experimental period (Figure 11).

The $\mathrm{pH}$ signal was decreasing during the experimental period (Figure 11(A)). As this decrease in $\mathrm{pH}$ could not be explained based on our microbiological knowledge, some tests were performed on the preparation of the artificial seawater fed to the reactor system. It showed that though the $\mathrm{pH}$ of the artificial seawater was adjusted to $\mathrm{pH} 7$, the chemical oxygen scavenger subsequently supplied to the medium significantly reduced the $\mathrm{pH}$. The most realistic explanation of the decreasing $\mathrm{pH}$ during the experiment was a chemically caused decrease in the $\mathrm{pH}$ of the inlet medium to the reactor, rather than a microbiological effect within the reactor itself. Correspondingly, no correlation between the reactor outlet $\mathrm{pH}$ and the planktonic cell number was observed (Figure 11(B)). 

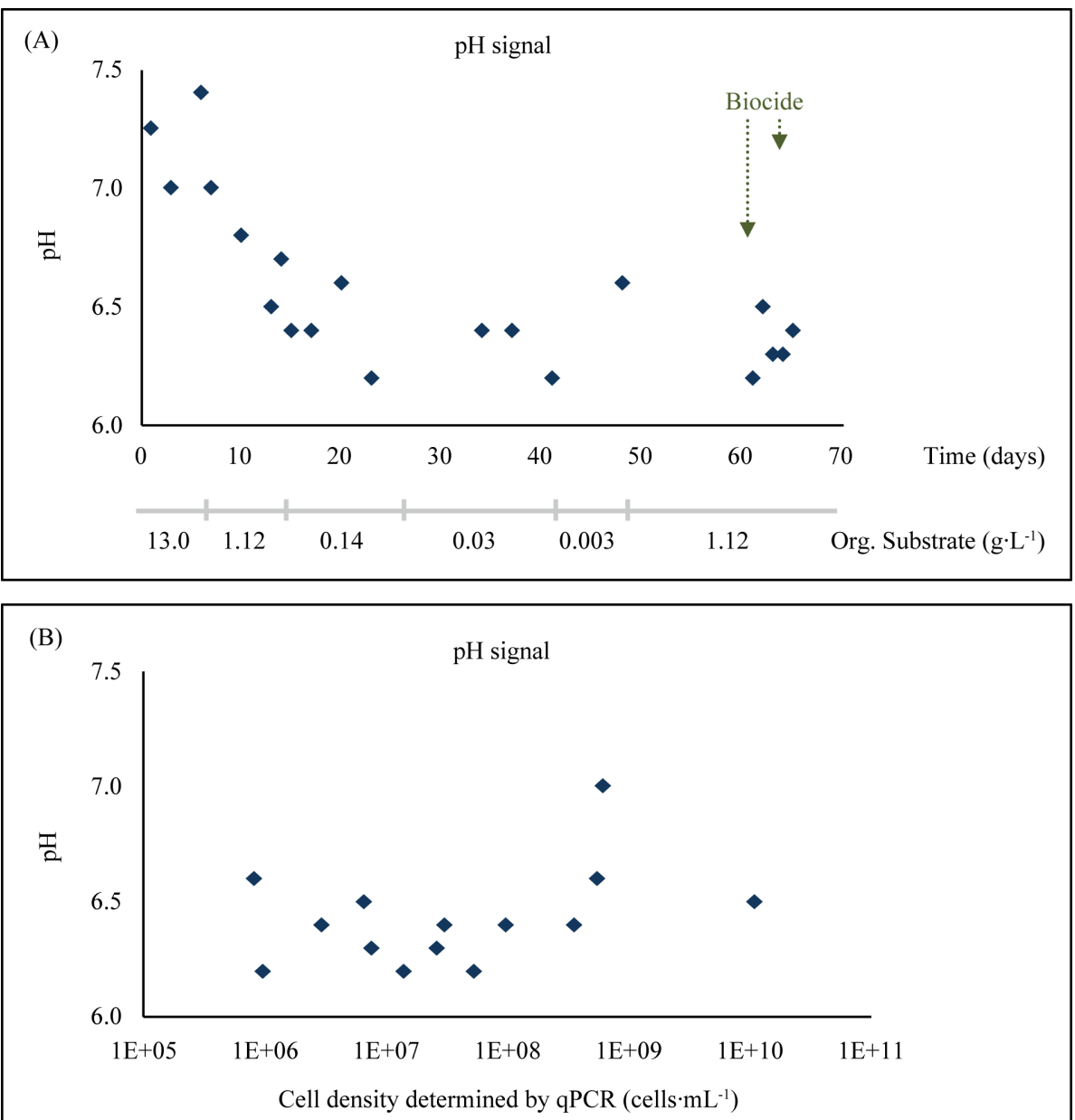

Figure 11. Reactor outlet $\mathrm{pH}$ measured by electrochemical sensor. (A) The $\mathrm{pH}$ signal as a function of time and (B) a correlation between the $\mathrm{pH}$ and cell numbers determined by qPCR. In (A), the lower $\mathrm{X}$-axis shows the organic substrate supply (in $\mathrm{g} \cdot \mathrm{L}^{-1}$ ) to the reactor. The green arrows indicate biocide addition (2000 ppm and $4000 \mathrm{ppm}$, respectively).

As $\mathrm{pH}$ is affected by many types of both chemical and microbiological processes, it may not be a suitable singleanalyte strategy for monitoring the microbiological processes in the injection water system.

\subsubsection{Electrochemical Sensor Measurements of ORP}

Metabolic activity in living organisms is based on chemical oxidation-reduction (redox) reactions [19] [21]. One way to measure the overall microbiological activity in an aqueous system would thus be by measuring the ORP of the liquid, which reflects the activity or strengths of electron acceptors and donors in relation to their concentrations.

The ORP of the reactor outlet was continuously monitored using an ORP minisensor. During the first 17 days of the experiment, the sensor worked stably, and the sensor signal ranged between an ORP of 500 to 1000. No clear-cut decrease or increase in the ORP could be observed with time. After Day 17, the sensor started behaving very instable, and the signal during one day of measurement could fluctuate between positive and negative ORP values. Electrochemical monitoring of ORP did therefore not appear as a reliable technology for monitoring microbial activity in the company injection water system.

\section{Conclusions}

Five single-analyte strategies were evaluated in a laboratory-scale setup to determine their applicability for the 
automated monitoring of microbial activity. Among the evaluated strategies, the simplest procedures suitable for automated cell enumeration were the staining of cells with photoreactive DNA dyes (PicoGreen and SYBR Green), followed by quantification of fluorescence signals. Given proper optimization of DNA staining and fluorescence detection, it is expected that this method can be used for an automated, online determination of microbial activity in Saudi Aramco's injection water system.

The other four single-analyte measuring principles tested in the laboratory setup were deemed less suitable for automation and/or reliable for use in the detection of microbial activity in the injection water system. These four principles were: luminescence assay for ATP, detection and electrochemical measurements of $\mathrm{H}_{2} \mathrm{~S}$, determination of $\mathrm{pH}$ by electrochemical sensor, and measurement of ORP.

Based on the experimental results, staining of cells with DNA-binding fluorescent dyes was identified to hold a very promising potential for automated detection of microbial activity. This work will be integrated in a prototype of automated microbial sensor for real-time monitoring of the injection water system, with optimized staining procedures and fluorescence detection hardware, which will be presented in a subsequent paper.

\section{Acknowledgements}

The authors would like to acknowledge the Saudi Aramco Oil Company (Saudi Aramco) for granting permission to publish this paper.

\section{References}

[1] Al-Moniee, M.A., Juhler, S., Sørensen, K., Al-Abeedi, F.N., Lundgaard, T. and Sanders, P.F. (2014) A Review of Saudi Aramco's Water Flooding System and Methods for Monitoring Microbial Activity. Proceedings of 15th Middle East Corrosion Conference, Bahrain, 2-5 February 2014, 1-19.

[2] Ren, H., Wang, W., Liu, Y., Liu, S., Lou, L., Cheng, D., He, X., Zhou, X., Qiu, S., Fu, L., Liu, J. and Hu, B. (2015) Pyrosequencing Analysis of Bacterial Communities in Biofilms from Different Pipe Materials in a City Drinking Water Distribution System of East China. Applied Microbiology and Biotechnology, 99, 10713-10724. http://dx.doi.org/10.1007/s00253-015-6885-6

[3] Teske, A., Wawer, C., Muyzer, G. and Ramsing, N.B. (1996) Distribution of Sulfate-Reducing Bacteria in a Stratified Fjord (Mariager Fjord, Denmark) as Evaluated by Most-Probable-Number Counts and Denaturing Gradient Gel Electrophoresis of PCR-Amplified Ribosomal DNA Fragments. Applied Environmental Microbiology, 62, 1405-1415.

[4] Pope, D.H. and Pope, R.M. (1998) Guide for the Monitoring and Treatment of Microbiologically Influenced Corrosion in the Natural Gas Industry. GRI Report GRI-96/0488, Gas Research Institute, Des Plaines.

[5] Vester, F. and Ingvorsen, K. (1998) Improved Most-Probable-Number Method to Detect Sulfate-Reducing Bacteria with Natural Media and a Radiotracer. Applied Environmental Microbiology, 64, 1700-1707.

[6] Zhu, X.Y. and Kilbane II, J.J. (2004) Molecular Tools in Microbial Corrosion. In: Vazquez-Duhalt, R. and QuinteroRamirez, R., Eds., Petroleum Biotechnology: Development and Perspectives, Elsevier Science, Amsterdam, 219-232.

[7] Zhu, X.Y., Modi, H., Ayala, A. and Kilbane II, J.J. (2006) Rapid Detection and Quantification of Microbes Related to Microbiologically Influenced Corrosion Using Quantitative Polymerase Chain Reaction. Corrosion, 62, 950-955. http://dx.doi.org/10.5006/1.3278233

[8] NACE Standard TM0194-2004 (2004) Field Monitoring of Bacterial Growth in Oilfield and Gas Systems. NACE, Houston.

[9] Singer, V.L., Jones, L.J., Yue. S.T. and Haugland, R.P. (1997) Characterization of PicoGreen Reagent and Development of a Fluorescence-Based Solution Assay for Double-Stranded DNA Quantitation. Analytical Biochemistry, 249, 228-238. http://dx.doi.org/10.1006/abio.1997.2177

[10] Tranvik, L.J. (1997) Rapid Fluorometric Assay of Bacterial Density in Lake Water and Seawater. Limnology and Oceanography, 42, 1629-1634. http://dx.doi.org/10.4319/lo.1997.42.7.1629

[11] Dragan, A.I., Pavlovic, R., McGivney, J.B., Casas-Finet, J.R., Bishop, E.S., Strouse, R.J., Schenerman, M.A. and Geddes, C.D. (2012) SYBR Green I: Fluorescence Properties and Interaction with DNA. Journal of Fluorescence, 22, 1189-1199. http://dx.doi.org/10.1007/s10895-012-1059-8

[12] Marie, D., Partensky, F., Jacquet, S. and Vaulot, D. (1997) Enumeration and Cell Cycle Analysis of Natural Populations of Marine Picoplankton by Flow Cytometry Using the Nucleic Acid Stain SYBR Green I. Applied Environmental Microbiology, 63, 186-193.

[13] Tarnowski, B.I., Spinale, F.G. and Nicholson, J.H. (1991) DAPI as a Useful Stain for Nuclear Quantitation. Biotechnic \& Histochemistry, 66, 296-302. http://dx.doi.org/10.3109/10520299109109990 
[14] Kapuscinski, J. (1995) DAPI: A DNA-Specific Fluorescent Probe. Biotechnic \& Histochemistry, 70, 220-233. http://dx.doi.org/10.3109/10520299509108199

[15] Maruyama, A. and Sunamura, M. (2000) Simultaneous Direct Counting of Total and Specific Microbial Cells in Seawater, Using a Deep-Sea Microbe as Target. Applied Environmental Microbiology, 66, 2211-2215. http://dx.doi.org/10.1128/AEM.66.5.2211-2215.2000

[16] Hersman, L.E. and Temple, K.L. (1979) Comparison of ATP, Phosphatase, Pectinolyase, and Respiration as Indicators of Microbial Activity in Reclaimed Coal Strip Mine Spoils. Soil Science, 127, 70-73. http://dx.doi.org/10.1097/00010694-197902000-00002

[17] Zelles, L., Adrian, P., Bai, Q.Y., Stepper, K., Adrian, M.V., Fischer, K., Maier, A. and Ziegler, A. (1991) Microbial Activity Measured in Soils Stored under Different Temperature and Humidity Conditions. Soil Biology and Biochemistry, 23, 955-962. http://dx.doi.org/10.1016/0038-0717(91)90176-K

[18] Dzierzewicz, Z., Cwalina, B., Chodurek, E. and Wilczok, T. (1997) The Relationship between Microbial Metabolic Activity and Biocorrosion of Carbon Steel. Research in Microbiology, 148, 785-793. http://dx.doi.org/10.1016/S0923-2508(97)82454-0

[19] Hambrick III, G.A., DeLaune, R.D. and Patrick Jr., W.H. (1980) Effect of Estuarine Sediment pH and Oxidation-Reduction Potential on Microbial Hydrocarbon Degradation. Applied Environmental Microbiology, 40, 365-369.

[20] Aciego Pietri, J.C. and Brookes, P.C. (2008) Relationships between Soil pH and Microbial Properties in a UK Arable Soil. Soil Biology and Biochemistry. 40, 1856-1861. http://dx.doi.org/10.1016/j.soilbio.2008.03.020

[21] Hewitt, L.F. (1948) Oxidation-Reduction Potentials in Bacteriology and Bio-Chemistry. London County Council, London. 